\title{
RESPIRACIÓN Y PARÁMETROS RELACIONADOS DURANTE LA MADURACIÓN DEL CHICOZAPOTE COSECHADO EN LA PENÍNSULA DE YUCATÁN ${ }^{1}$
}

\author{
NIDELVIA BOLÍVAR-FERNÁNDEZ², CRESCENCIANO SAUCEDO-VELOZ, ENRIQUE SAURI-DUCH
}

RESUMEN - El chicozapote es un fruto nativo de América, considerado originario de la Península de Yucatán. Este fruto es clasificado como climatérico, dependiendo el momento del climaterio de factores externos que inducen la producción de etileno. En la ruta biosintética del etileno, la enzima Ácido 1-Aminocicloproano-1-Carboxílico Oxidasa (ACC Oxidasa) es responsable de la oxidación de Ácido 1-Aminocicloproano-1-Carboxílico (ACC) a etileno, lo que constituye la última etapa de su biosíntesis. Debido a que los procesos metabólicos relacionados con el proceso de respiración de este fruto durante su maduración poscosecha aún no son claros, el objetivo de este trabajo fue estudiar los principales cambios de la respiración y parámetros relacionados durante la maduración. Se cosecharon frutos de chicozapote (Manilkhara achras) sazones en el campo experimental de la Universidad Nacional Autónoma de Chapingo en Yucatán y se dejaron madurar a temperatura ambiente $\left(28 \pm 2^{\circ} \mathrm{C}\right)$, evaluando la velocidad de producción de $\mathrm{CO}_{2}$ y etileno en frutos enteros y destruyendo seis cada día, para realizar las determinaciones establecidas para la pulpa de este fruto. Los resultados indicaron que en el fruto chicozapote Selección Campeche, cultivado en Yucatán el pico climatérico se presenta alrededor del quinto día después de la cosecha y coincide con un pico de etileno y la máxima actividad de la enzima ACC Oxidasa. La enzima Polifenol Oxidasa (PPO) utiliza como sustrato a las antocianinas y los taninos. El etanol aparece como un producto de descomposición y no como sustrato durante la síntesis de etileno. Antocianinas y acetaldehído durante la madurez comestible y la senescencia en la pulpa de este fruto, contribuyen al color de la misma.

Terminós para indexación: Manilkhara achras, catalizadores, frutos tropicales.

\section{RESPIRATION AND RELATED PARAMETERS OF MATURATION IN HARVESTED Chicozapote IN THE YUCATAN PENINSULA}

\begin{abstract}
The sapodilla is a fruit native to America, considered to be originated from the Yucatan Peninsula. It is classified as a climacteric fruit, whose ripening process depends on external factors that induce the production of ethylene. In the biosynthetic pathway of ethylene, ACC oxidase enzyme is responsible for the oxidation of ACC to ethylene, which is the last stage of its biosynthesis. Because the metabolic processes related to the respiratory process of the fruit during postharvest maturation are still unclear, the aim of this work was to study the main changes in respiration and related parameters during ripening. Sapodilla (Manilkhara achras) season fruits were harvested in the experimental field of the National Autonomous University of Chapingo in Yucatan and allowed to ripen at room temperature $\left(28 \pm 2{ }^{\circ} \mathrm{C}\right)$, evaluating the rate of $\mathrm{CO}_{2}$ and ethylene production in whole fruit, destroying six of them each day, to perform the determinations in the pulp. The results indicated that for the selection sapodilla fruits Campeche, grown in Yucatan, the climacteric peak occurs around the fifth day after harvest and coincides with a peak of ethylene and the maximum activity of the enzyme ACC oxidase. The PPO enzyme uses as substrate the anthocyanins and tannins. Ethanol appears as a breakdown product and not as a substrate for the synthesis of ethylene. Anthocyanins and acetaldehyde in the edible pulp of this fruit, during the maturity and senescence, contribute to its color.
\end{abstract}

Index terms: Manilkhara achras, catalizadores, tropics fruits.

\footnotetext{
${ }^{1}$ Trabalho Sinfruit 110 - Simpósio Internacional de Fruticultura - Avanços na Fruticultura (17 a 21 Outubro) ${ }^{2}$ Universidad Autónoma de Campeche. Ave. Agustin Melgar s/n entre calle 20 y Juan de la Barrera, Colonia Lindavista C.P. 24039 Campeche, Campeche. E-mail: njboliva@uacam.mx
} 


\section{INTRODUCCIÓN}

Se estima que en las regiones tropicales y subtropicales del mundo se producen más de 600 tipos de frutas diferentes con una amplia variedad de colores, sabores y aromas que las caracterizan. Sin embargo, en la actualidad se explotan comercialmente menos de 25 especies. Un fruto exótico nativo de las regiones tropicales de América es el chicozapote (Achras sapota L.). Este fruto es conocido con otros nombres en diferentes países, tales como sapodilla (Estados Unidos), sapota o chiku (India), chico o chicozapote (México) y níspero (Venezuela). Se considera originario de la Península de Yucatán y posiblemente de otros lugares cercanos en la parte sur de México (BÁEZ et al., 1997). Este fruto es clasificado como climatérico, ya que presenta un incremento en la respiración o pico climatérico después de la cosecha. Al igual que otros frutos climatéricos, el chicozapote madura fuera del árbol. En la variedad Calcuta Round se reporta un patrón respiratorio con un máximo climatérico de $140 \mathrm{mg} \mathrm{CO}{ }_{2} \cdot \mathrm{kg}^{-1} \cdot \mathrm{h}^{-1}$ al octavo día después del corte de la planta y mantenido a $24-28^{\circ} \mathrm{C}$ y actividad enzimática durante la maduración del mismo (LAKSHMINARAYANA; SUBRAMANYAN, 1966). A su vez, Baez et al., (1997), en sus estudios de fisiología poscosecha de frutos de Chicozapote durante condiciones de mercadeo, encontró que la mayor producción de $\mathrm{CO}_{2}$ se presentó el sexto día con valores de $27 \mathrm{ml} \cdot \mathrm{kg}^{-1} \cdot \mathrm{h}^{-1}$. Este incremento en la respiración se vio precedido por un incremento en la producción de etileno, que alcanzó su pico al quinto día con $1.7 \mu 1 . \mathrm{kg}^{-1} \cdot \mathrm{h}^{-1}$. En la ruta biosintética del etileno la enzima ACC Oxidasa es la responsable de la oxidación de ACC a etileno, lo que constituye la última etapa de su biosíntesis. Esta enzima se denomina clásicamente "Enzima Formadora de Etileno" (EFE) y está presente en la mayoría de los tejidos vegetales.

La actividad de ACC Oxidasa se inhibe por iones $\mathrm{CO}_{2}$, ácido $\mu$ - aminoisobutírico y temperaturas superiores a $35^{\circ} \mathrm{C}$ y es altamente dependiente del Oxígeno (VERVEREDIS; JOHN, 1991), siendo clara la relación existente entre ACC Oxidasa, $\mathrm{CO}_{2}$ y etileno, que son parámetros a estudiar en esta investigación. Por otro lado, durante el metabolismo primario, el acetaldehído es un compuesto que resulta de la decarboxilación del ácido pirúvico en una reacción prácticamente irreversible, que en presencia de NADH se reduce a etanol (MATTO; SUTTLE, 1991). En situaciones normales acetaldehído y etanol se producen en pequeñas cantidades, sin embargo, cuando por algún desorden fisiológico existe acumulación de piruvato, estos alcoholes incrementan su concentración, relacionándose el oscurecimiento celular con altas concentraciones de acetaldehído (ARÉVALO, 1999).

Respecto a los compuestos fenólicos se sabe que están relacionados con el color y son fácilmente detectables. Muchas frutas poseen un sistema enzimático que es capaz de utilizar como sustrato a las antocianinas (un tipo de fenoles), dentro de este complejo enzimático se encuentra la enzima conocida como Polifenol Oxidasa (PPO) (VAN BUREN et al., 1960). Durante algunas décadas, se ha acumulado evidencia de que la astringencia de algunos frutos es debida a la presencia de compuestos fenólicos con un cierto grado de despolimerización. Compuestos fenólicos simples tales como ácidos hidroxicinámicos, catequinas y antocianinas, no son astringentes, pero dímeros de las flavanas muestran este carácter (VAN BUREN et al., 1960). En muchos frutos la astringencia está íntimamente relacionada con la reacción de oscurecimiento de los taninos condensados (VAN BUREN, 1970). Dado que el color es considerado un parámetro de calidad y en él influyen los compuestos fenólicos, la concentración de acetaldehído, la actividad de oxidasas y el proceso de maduración, el objetivo de este trabajo es identificar los principales cambios enzimáticos y en la respiración durante el proceso de maduración poscosecha del fruto chicozapote cosechado en la Península de Yucatán, así como definir la correlación que existe entre ellos.

\section{METODOLOGÍA}

Se cosecharon sesenta frutos de chicozapote sazones en el campo experimental de la Universidad Nacional Autónoma de Chapingo, en Temozón Norte, Yucatán. Los frutos se dividieron de la siguiente forma: Seis frutos para evaluar velocidad de respiración y producción de etileno cada 24 horas. Cincuenta y cuatro frutos se dejaron madurar a temperatura ambiente $\left(28 \pm 2^{\circ} \mathrm{C}\right)$, destruyendo seis cada día para extraer la pulpa y hacer las determinaciones establecidas.

\section{MÉTODOS ANALÍTICOS}

Para las determinaciones de antocianinas, taninos, etanol, acetaldehído, y actividad de las enzimas ACC Oxidasa y PPO, se extrajo manualmente la pulpa del fruto, se picó finamente y homogeneizó, para posteriormente darle el tratamiento indicado por cada técnica. 


\section{TASA DE RESPIRACIÓN Y PRODUCCIÓN DE ETILENO}

Se utilizó un sistema estático cerrado (VARGAS, 1999). Se utilizaron seis frutos, cada uno encerrado de manera independiente. El análisis de los gases se llevó a cabo por cromatografía de gases utilizando un cromatógrafo Varian Star con dos detectores en serie, TCD (Conductividad Térmica) para determinar $\mathrm{CO}_{2}$; y FID (Ionización de flama) para determinar etileno. Se utilizó una columna megaboro de $15 \mathrm{~m}$ de Porapak Q y helio como gas portador. Las temperaturas del método de trabajo utilizado para determinar $\mathrm{CO}_{2}$ y etileno, son las siguientes: Temperatura de la columna: $80^{\circ} \mathrm{C}$, Temperatura del inyector: $120^{\circ} \mathrm{C}$, Temperatura del detector FID: $230^{\circ} \mathrm{C}$, Temperatura del detector TCD: $210^{\circ} \mathrm{C}$. Los resultados se expresan en ml. $\mathrm{kg}^{-1} \cdot \mathrm{h}^{-1}$ de $\mathrm{CO}_{2}$ y $\mu l \cdot \mathrm{kg}^{-1} \cdot \mathrm{h}^{-1}$ de etileno.

Color de la pulpa: Se determinó utilizando un colorímetro de laboratorio triestímulo por reflexión marca Minolta, directamente en la pulpa, que se extrajo de forma manual y se colocó en una caja de petri. La determinación de color se realizó en la parte central de la caja que contenía un centímetro de espesor de pulpa. Se leyeron los valores de $\underline{L}$, a y $\underline{b}$, calculándose el tono o ángulo matiz como el arc tan (b/a). Los resultados se expresaron como tono, ángulo matiz o hue.

Firmeza de la pulpa: Cada día se determinó firmeza en pulpa $\left(\mathrm{kgf} / \mathrm{cm}^{2}\right)$, utilizando un texturómetro manual Fruit Tester Ft 327 y 011, evaluando la resistencia a la penetración en frutos cortados a la mitad.

Antocianinas: Se determinó por medio de la técnica espectofotométrica modificada (ALIA, 1999), utilizada en mamey. La extracción de las antocianinas se hizo con ácido clorhídrico en metanol y se expresaron como mg de antocianinas por $100 \mathrm{~g}$ de muestra.

Taninos: (AOAC, 1980 adaptada por Navarro 1988 para chicozapote). Se utiliza el reactivo de Folin - Dennis para extraer el compuesto y se hace reaccionar con carbonato de sodio. El cambio de color se determina espectofotométricamente a $760 \mathrm{~nm}$ y los resultados se expresan como \% de ácido tánico.

Etanol y acetaldehído: Se utilizó un sistema estático cerrado (ARÉVALO, 1999). Se utilizaron diez gramos de pulpa finamente picada por cada fruto evaluado, cada fruto encerrado de manera independiente, calentado a baño maría a una temperatura de $70^{\circ} \mathrm{C}$ durante diez minutos. El análisis se llevó a cabo por cromatografía de gases utilizando un cromatógrafo Varian Star con dos detectores, TCD y FID, utilizando para este caso el de Ionización de flama. Se utilizó una columna megaboro de $15 \mathrm{~m}$ de Porapak Q y helio como gas portador. Las temperaturas (programadas) del método de trabajo son las siguientes: Temperatura inicial de la columna: $80^{\circ} \mathrm{C}$, Temperatura final de la columna: $200^{\circ} \mathrm{C}$, Temperatura del inyector: $120^{\circ} \mathrm{C}$, Temperatura del detector FID: $230^{\circ} \mathrm{C}$, Temperatura del detector TCD: $210^{\circ} \mathrm{C}$, Temperatura del filamento TCD: $240^{\circ} \mathrm{C}$.

Actividad de la enzima ACC oxidasa: (GONZÁLEZ, 1995), se determinó por cromatografía de gases, cuantificando la cantidad de etileno producido en $\mu l . \mathrm{kg}^{-1} \cdot \mathrm{h}^{-1}$, previa saturación de los tejidos a estudiar con ACC.

Actividad de la enzima Polifenoloxidasa (PPO): Se aplicó la metodología recomendada por OAKTAY et al. (1995), modificada y adaptada para chicozapote por Medrano (1999). Para la medición de la actividad enzimática se hizo reaccionar el extracto enzimático con pirocatecol como sustrato bajo condiciones estandarizadas y se monitoreó espectofotometricamente la formación de quinonas a $420 \mathrm{~nm}$. El resultado se expresa como Unidades de actividad enzimática de PPO. Una unidad $=0.001$ absorbancia $/ \mathrm{min} / \mathrm{g}$ de tejido.

\section{RESULTADOS Y DISCUSIÓN}

En el cuadro 1 se pueden observar los resultados promedio de seis unidades experimentales, obtenidos durante la realización de este trabajo.

En la velocidad de producción de etileno, se observa un valor alto durante el primer día de maduración poscosecha, asociado al estrés del fruto en el momento en que es desprendido del árbol; inmediatamente, la velocidad de producción de este gas comienza a disminuir hasta el cuarto día, incrementándose nuevamente durante el quinto día, que es cuando se alcanza el pico de etileno característico de los frutos climatéricos. Por otro lado, el patrón respiratorio alcanza la mayor concentración de $\mathrm{CO}_{2}$ durante el quinto día, coincidente con un máximo relativo en la velocidad de producción de etileno y no posterior a él. Este comportamiento es atribuible al hecho de que las altas concentraciones de etileno presentes durante los primeros días de maduración poscosecha inducen la aparición del climaterio, acelerado por el incremento relativo de etileno que se presenta paralelamente. La actividad de la enzima ACC Oxidasa presenta una tendencia similar a la seguida por el etileno durante el proceso de maduración, mostrando una correlación entre la enzima ACC Oxidasa y el etileno. También se observó que la velocidad de producción de etileno, la producción de bióxido de carbono y la actividad de la enzima ACC oxidasa, presentan un valor relativamente alto 
el día cinco, que es cuando el fruto empieza a cambiar sensiblemente al tacto indicando que empieza a madurar $\left(6.22 \mathrm{kgf} / \mathrm{cm}^{2}\right)$, tal como se observa en la figura 1.

La velocidad de producción de $\mathrm{CO}_{2}(92.82 \mathrm{ml}$. $\mathrm{kg}^{-1} \cdot \mathrm{h}^{-1}$ en el climaterio) es extremadamente alta, comparada, por ejemplo, con las alcachofas y la col de Bruselas cuya producción de $\mathrm{CO}_{2}$ está clasificada como alta (IMIT, 1994).

Respecto a la ruta de biosíntesis del etileno, además de la metionina se reportan como sus precursores al etanol y la glucosa, entre otros (DAVIES, 1987). Al analizar los datos obtenidos para el tipo criollo sobresaliente de chicozapote estudiado, se observa que el etanol presenta durante los dos primeros días de maduración un comportamiento similar al del etileno, cambiando esta relación a partir del tercer día, cuando el etileno disminuye $\mathrm{y}$ el etanol se incrementa, siguiendo este comportamiento antagónico durante los días 6, 7, 8 y 9. A su vez, el acetaldehído tiende a comportarse de forma similar al etanol. Las tendencias observadas nos llevan a sugerir que el etanol y el acetaldehído en las concentraciones encontradas, son productos de descomposición y no sustratos en la síntesis del etileno (PEÑA et al., 2001). Las concentraciones similares de etanol y acetaldehído durante todo el proceso de maduración y su incremento al inicio de la senescencia indican que el incremento de estos volátiles está relacionado con desórdenes fisiológicos en el fruto. En el cuadro 1 se observa que, mientras la concentración de antocianinas y taninos decrece, la actividad de la enzima Polifenol Oxidasa (PPO) se incrementa, lo que sugiere que la enzima PPO utiliza antocianinas y taninos como sustrato para formar quinonas, disminuyendo sensiblemente la actividad de la enzima PPO cuando las concentraciones del sustrato son cercanas a cero. Es importante señalar que los valores más altos de taninos se observan en los primeros días de maduración poscosecha, lo cual se relaciona perfectamente con el grado de astringencia reportado para el chicozapote cuando aún no está listo para comer (NAVARRO, 1988).

Respecto al color de la pulpa, el ángulo matiz mínimo se presenta el día nueve, paralelo a la menor concentración de antocianinas, cuando el fruto está sobremaduro y no es agradable al paladar.

También se observa que todos los ángulos matiz se encuentran en el primer cuadrante dentro de un plano cartesiano de coordenadas $(\mathrm{x}=\mathrm{a}, \mathrm{y}=\mathrm{b}) \mathrm{y}$ están comprendidos entre 50 y 71, que corresponden al color rojo amarillo en el sistema de medición de color CIELab, sin embargo, es importante resaltar que mientras que en el día uno (fruto sazón), el valor promedio de "a" (tendencia al rojo) es 10.12 y "b" (tendencia al amarillo) es 23.95; en el día nueve (fruto sobremaduro), "a" es 10.73 y "b" es 13.1 , lo que sugiere que la tonalidad rojiza se acentúa levemente en tanto que la tendencia al amarillo decrece significativamente durante el proceso de maduración.

CUADRO 1. Valores promedio obtenidos durante la maduración poscosecha del fruto chicozapote almacenado a $26 \pm 2^{\circ} \mathrm{C}$.

\begin{tabular}{|c|c|c|c|c|c|c|c|c|}
\hline Días & $\begin{array}{c}\% \text { de } \\
\text { ácido } \\
\text { tánico }\end{array}$ & $\begin{array}{c}\text { mg de } \\
\text { Antocia } \\
\text { Ninas/100g } \\
\text { de pulpa }\end{array}$ & $\begin{array}{c}\mathrm{U} \text { de } \\
\mathrm{PPO}\end{array}$ & $\begin{array}{c}\mathrm{mg} \text { de Acetaldeh } \\
\text { ído/100g de pulpa }\end{array}$ & $\begin{array}{c}\text { mg de } \\
\text { Etanol/100g } \\
\text { de pulpa }\end{array}$ & $\begin{array}{c}\text { ACC } \\
\text { oxidasa }(\mu 1 . \\
\mathrm{Kg}^{-1} \cdot \mathrm{h}^{-1} \mathrm{de} \\
\text { etileno })\end{array}$ & $\begin{array}{c}\text { Etileno } \\
\mu 1 \\
\mathrm{Kg}^{-1} \cdot \mathrm{h}^{-1}\end{array}$ & $\begin{array}{c}\mathrm{CO}_{2} \mathrm{ml}^{-1} \\
\mathrm{Kg}^{-1} \cdot \mathrm{h}^{-1}\end{array}$ \\
\hline 1 & $\mathbf{3 . 2}^{\mathrm{a}}$ & $1.22^{\text {abc }}$ & $1.12^{\mathrm{a}}$ & $\mathbf{1 . 3 8 9}$ & $\mathbf{1 . 2 7 0}$ & 98.39 & 65.05 & 59.16 \\
\hline 2 & $3.1^{\text {ab }}$ & $2.21^{\text {de }}$ & $2.25^{\mathrm{a}}$ & 0.0798 & 0.842 & 87.34 & 30.5 & 47.89 \\
\hline 3 & $3.0^{\text {ab }}$ & $\mathbf{2 . 4 8}^{\mathrm{e}}$ & $3.46^{\mathrm{a}}$ & 0.330 & 1.040 & 34.66 & 26.13 & 58.55 \\
\hline 4 & $2.8^{\mathrm{ab}}$ & $1.72^{\text {cde }}$ & $5.33^{\mathrm{a}}$ & 0.794 & 1.266 & 28.40 & 22.67 & 76.5 \\
\hline 5 & $2.6^{\text {abc }}$ & $1.31^{\text {bcd }}$ & $8.42^{\mathrm{a}}$ & 0.996 & 1.268 & $\mathbf{7 7 . 2 4}$ & $\mathbf{3 0 . 9 3}$ & $\mathbf{9 2 . 8 2}$ \\
\hline 6 & $2.3^{\text {bc }}$ & $1.32^{\text {bcd }}$ & $29.6^{\mathrm{b}}$ & 1.180 & 1.272 & 41.33 & 23.2 & 55.25 \\
\hline 7 & $2.0^{\mathrm{c}}$ & $1.33^{\text {bcd }}$ & $48.6^{\mathrm{c}}$ & 2.095 & 1.276 & 28.28 & 21.6 & 55.16 \\
\hline $8^{*}$ & $0.4^{\mathrm{d}}$ & $0.51^{\mathrm{ab}}$ & $\mathbf{5 9 . 2}^{\mathrm{d}}$ & 3.845 & 1.292 & 28.32 & 16.0 & 48.41 \\
\hline $9^{* *}$ & $0.2^{\mathrm{d}}$ & $0.35^{\mathrm{a}}$ & $50.4^{\mathrm{c}}$ & $\mathbf{5 . 4 3 0}$ & $\mathbf{3 . 1 1 5}$ & 18.98 & 13.6 & 35.55 \\
\hline
\end{tabular}

* Fruto maduro, listo para comer.

** Fruto sobremaduro

Letras diferentes en la misma columna son indicadores de una diferencia significativa con un $95 \%$ de confianza. 
FIGURA 1. Cambios en la pulpa del chicozapote durante la maduración pososecha

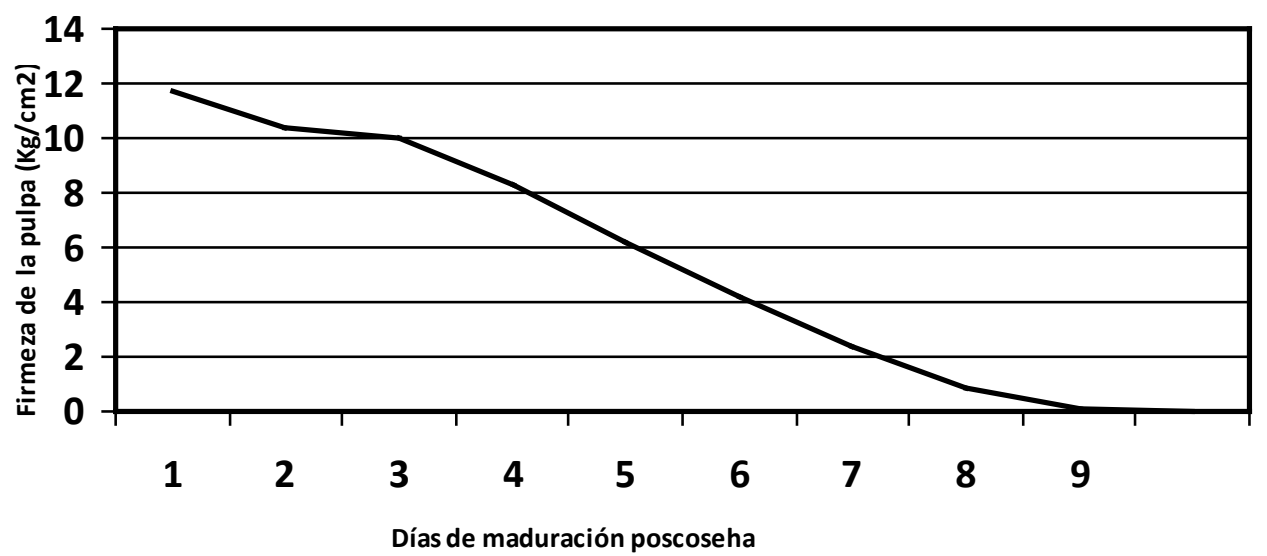

\section{CONCLUSIONES}

En el fruto chicozapote cultivado en la Península de Yucatán, el pico climatérico se presenta en promedio alrededor del quinto día después de la cosecha y coincide con un pico en la producción de etileno y la máxima actividad de la enzima ACC Oxidasa. La enzima PPO utiliza como sustrato a las antocianinas y los taninos. El etanol aparece como un producto de descomposición y no como sustrato durante la síntesis de etileno. Las antocianinas y el acetaldehído presentes durante la madurez comestible y la senescencia en la pulpa de este fruto contribuyen a su color característico.

\section{REFERENCIAS}

AOAC. Official methods analysis. Association of Official Analytical Chemists. Ed., Washington, D.C. 832 p. 1990.

ARÉVALO, L.; SAUCEDO, C.; COLINAS, M.T. Y MENA, G. Aplicación de ceras y CEPA en frutos de chicozapote (Manilkara sapota L.). Revista Chapingo, Serie Horticultura, v. 2. 83-88. 1999.

BROUGHTON, W.H.; WONG, H.C. Storage conditions and ripening of chiku fruits Achras sapota. Scientia Horticulturae, 10(4): 377-385. 1979.

CHEYNIER, V.; SOUQUET, J.M.; KONTEK, A.; MOUTOUNET, M. Anthocyanin degradation in oxidising grape Musts. Journal Science Food Agric. 66: 283-288. 1994.
HODGE, J.E.; HOFREITER, B.T. Determination of reducing sugars and carbohydrates. In: WHISTLER, R.L.; WOLFROM, M.L. (Eds.). Academic Press, New York, p. 380-394. 1962.

\section{LAKSHMINARAYANA, S.; SUBRAMANYAM,} $\mathrm{H}$. Physycal, chemical and physiological changes in sapota fruit (Achras sapota L.) during development and ripening. Journal Food Sci. Technol. 3: 151 154. 1966.

LAKSHMINARAYANA, S. Sapodilla and pickly pear. In: Magy, S. and Shaw, P.E. (Eds.) Tropical and subtropical fruits. AVI, Publ. Conn. Inc. Wesport, Conn., Pp. 415-441. 1980.

MARQUEZ, L.; FLEURIET, A.; MACHEIZX. Fruit polyphenols oxidases. In: Lee, C.L. and Whitaker,R.J. (Ed.). Enzimatic browning and its prevention. A.C.S. Washington, D.C., Pp. 90-102. 1995.

MARTÍNEZ-TELLEZ Y LAFUENTE, M. Chilling induced changes in PAL, PDO y PPO activities in citrus flavedo tissue. Acta Horticulturae 343, p. 257.1993

MICKELBART, M.V. A potential crop for subtropical climates. In: J.Janick (ed.), Progress in new crops. HSHS Press, Alexandria, V.A. P. 439-446. 1996.

NELSON, N. A photometric adaptation of the Somogyi method for the determination of glucosa. Journal Biol. Chem: p.153 - 375. 1944. 
PARALKAR, P.; JOSHI, G.; SALVI, M. Studies on physicochemical changes in sapota (Manilkara achras (Mill)) cv. Kalipatti fruits. Indian Food Packer, 41(4): 11-18. 1987.

PÉREZ-TELLO, G.; BRISEÑO, T.; VARGAS, A.; DÍAZ-PÉREZ, J.; MARTÍNEZ-TELLEZ, M. Actividad de polifenoloxidasa y peroxidasa en frutos de mamey sapote (Pouteria sapota). Revista Iberoamericana de Tecnología Postcosecha, 1(2): 120-125. 1999.

PRADO, L.; HUERTA, S.; RODRÍGUEZ, G.; SAUCEDO, G. Avances en purificación y aplicación de enzimas en biotecnología. Revista de la Universidad Autónoma Metropolitana, Unidad Iztapalapa, División de Ciencias Biológicas, México. Pp. 329-331. 1999.
RAO, D.; CHUNDAWAT, B. Postharvest changes in respiration and enzyme activities in sapota (Manilkara achras (Mill) Fosberg). Indian J. Plant Physiology, XXXII(2): 105-109. 1989.

SELVARAJ, Y.; PAL, D. Changes in the chemical composition and enzyme activity of two sapodilla (Manilkara sapota) cultivars during development and ripening. J. Horticultural Science, 59(2): 275 281. 1984.

WARD, O. Hydrolitic enzymes. En Blanch, H.W., Drew, S. Y Wang, D.I. (Eds.) Comprehensive Biotechnology. Pergamon Press, New-York; 3:819 $-835.1985$. 